\title{
Near-field TEC response to the main shock of the 2008 Wenchuan earthquake
}

\author{
Edward L. Afraimovich ${ }^{1}$, Ding Feng ${ }^{2}$, Vladislav V. Kiryushkin ${ }^{1}$, and Elvira I. Astafyeva ${ }^{1,3}$ \\ ${ }^{1}$ Institute of Solar-Terrestrial Physics SB RAS, P.O. 291, Irkutsk, 664033, Russia \\ ${ }^{2}$ Institute of Geology and Geophysics, Chinese Academy of Sciences, Beijing, 100029, China \\ ${ }^{3}$ Dept. of Natural History Sciences, Hokkaido University, Kita-ku, N10 W8, Sapporo 060-0810, Japan
}

(Received September 25, 2008; Revised June 28, 2009; Accepted July 3, 2009; Online published January 26, 2011)

\begin{abstract}
We have registered near-field TEC response to the Wenchuan earthquake on 12 May 2008, for the first time. We found that an intensive $N$-shape shock-acoustic wave with a plane waveform and with half-period of about $200 \mathrm{sec}$ propagated south-eastward with a velocity of $600 \mathrm{~m} / \mathrm{s}$ for distance about $1000 \mathrm{~km}$. The wavefront of $N$-shaped disturbance was parallel with the earthquake rupture direction (from SW to $\mathrm{NE}$ ). The main directional lobe of shock-acoustic wave emitter is directed southeastward, i.e. transversely to the rupture. We suppose that the above properties of TEC response are determined by the geodynamics of the Wenchuan earthquake.
\end{abstract}

Key words: GPS, earthquakes, total electron content, Wenchuan earthquake.

\section{Introduction}

The method of ionosphere monitoring by GPS is widely used for detecting and studying ionospheric response to large earthquakes (EQ). Calais and Minster (1995) first observed anomalous signal in the time series of total electron content (TEC) in the period range 3-10 min after an earthquake that occurred in California, USA, on 17 January 1994. Frequency and propagation phase velocity (300$600 \mathrm{~m} / \mathrm{s}$ ) agreed with the results of numerical simulation for atmospheric gravity waves (AGW) caused by a rapid uplift and subsidence of the Earth' surface during the earthquake. The velocity was determined as a ratio of distance from an earthquake's epicenter to Sub-Ionospheric Point (SIP) to the time delay of perturbation registration in the corresponding SIP.

Afraimovich et al. (2001a) proposed a simple interferometric method for determining the angular characteristics of the wave vector and phase velocity of $N$-shape shockacoustic waves (SAW), generated during an earthquake. The authors used GPS-arrays, consisted of three sites, the distances between which do not exceed about one-half the wavelength of the perturbation (D1 method). This method provided an estimation of SAW parameters without a priori information about the site and time of a EQ main shock. But D1 method doesn't allow us to determine the form of phase front of SAW (plane or the spherical wavefront).

Afraimovich (2000) first suggested the concept of a new technology for detection of ionospheric disturbances using GPS arrays. According to this concept the TEC measurements along GPS line-of-sight (LOS) were considered as elements of nonequidistant phased antenna arrays of the acoustic detectors located at the ionospheric heights.

Copyright (c) The Society of Geomagnetism and Earth, Planetary and Space Sciences (SGEPSS); The Seismological Society of Japan; The Volcanological Society of Japan; The Geodetic Society of Japan; The Japanese Society for Planetary Sciences; TERRAPUB.

doi:10.5047/eps.2009.07.002
On the basis of this concept the different methods of space-time processing of TEC series were developed, including quasi-optimum algorithm, QOA (Afraimovich et al., 2002, 2006; Kiryushkin and Afraimovich, 2007). These algorithms realized the coherent summation of the TEC series accounting for space-time parameters of disturbance. In order to determine parameters of ionospheric perturbation the parameters values were varied. For each combination of the estimated parameters the normalized criterion function $C$ for the coherent sum of all TEC series and the reference signal were calculated. The largest maximum value $C_{\max }$ corresponds to the best-fit perturbation parameters.

In this paper we used our $D 1$ and $Q O A$ methods to study the near-field TEC response to very strong and disastrous Wenchuan earthquake which occurred on 12 May 2008.

\section{General Information about the Earthquake}

The Wenchuan earthquake of 12 May 2008 (magnitude 7.9) occurred at 06:28:01 UT as the result of rupture on a northeast striking reverse fault in the northwestern margin of the Sichuan Basin, China. The earthquake was the result of release of tectonic stresses accumulated by the convergence of slowly moving high Tibetan Plateau, to the west, against the Sichuan Basin and southeastern China (http://earthquake.usgs.gov).

The rupture started at the epicenter $(30.986 \mathrm{~N}, 103.364 \mathrm{E})$ and over the next $50 \mathrm{sec}$ travelled about $200 \mathrm{~km}$ toward the northeast, tearing apart the land along the front of the mountain range. The slip due to the earthquake in some places amounted as large as 9 meters (Parsons et al., 2008). The maximum vertical slippage occurred about $60 \mathrm{~km}$ northeast of the epicenter (Parsons et al., 2008).

Motion along the southern edge of the fault was predominantly dip slip (i.e., land on one side of the fault moving under land on the other side), leading to an increment of uplift of the mountain range and subsidence of the Sichuan basin. 


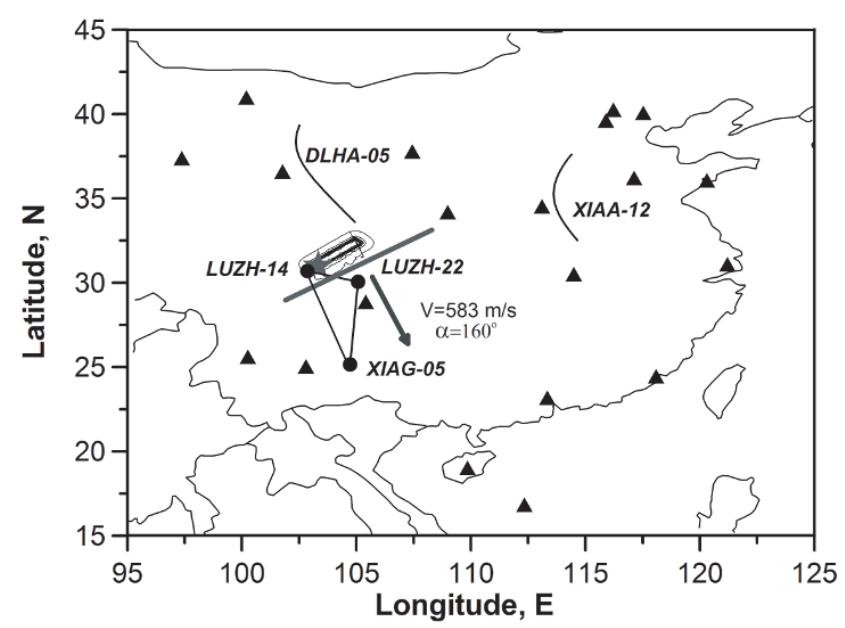

Fig. 1. Experimental geometry of GPS measurements during the Wenchuan earthquake on 12 May 2008. Gray star shows the epicenter's location. Isolines of Peak Ground Velocity are presented by thin lines near the epicenter. Location of the SIPs for the selected GPS sites and GPS satellite numbers LUZH-14, LUZH-22 and XIAG-05 at the moments of maximum of TEC deviation is shown by thick dots; solid line triangle represents the $D 1$ GPS array we used. Location of all used GPS sites is marked by shaded triangles. Gray line and arrow show the plane wave front and wave vector of excited shock-acoustic wave. Thin curves show the motion of SIPs in the northwest (DLHA-05) and the northeast (XIAA-12) direction from epicenter. The projection of magnetic field vector $\boldsymbol{B}$ to Earth's surface is shown by a dotted grey arrow.

Figure 1 shows the location of rupture using data of Peak Ground Velocity according the Finite Fault Model calculate by Ji and Hayes (2008). The earthquake epicenter is shown by an gray star. Isolines of Peak Ground Velocity are presented by thin lines near the epicenter. Similar results were obtained in the Caltech Tectonics Observatory (http://www.tectonics.caltech.edu/). The last slip model is slightly different, but the rupture direction is also from SW to NE.

Unfortunately IGS GPS sites in the near-field the source region of the Wenchuan earthquake are relatively sparse. Therefore we used GPS data at 27 GPS stations, which are belonging to the Crustal Movement Observation Network of China. Locations of all used GPS sites are marked in Fig. 1 by solid triangles.

The level of geomagnetic disturbances was quiet during the Wenchuan earthquake; the $K_{\mathrm{p}}$ index varied from 0 to 1 on 12 May 2008 (http://www.wdc.rl.ac.uk/cgibin/wdccl/secure/wdcdata).

\section{GPS Data Processing and Results}

Our methods are described in detail in Afraimovich et al. (2001a) and in Kiryushkin and Afraimovich (2007). We now briefly summarize the sequence of data processing procedures and results.

Out of a set of GPS sites, first, three sites (A, B, C) are selected for $D 1$ method. Site B is taken to be the center of a topocentric reference frame whose axis $x$ is directed east, and the axis $y$ is directed north. The receivers in this reference frame have the coordinates $\left(x_{\mathrm{A}}, y_{\mathrm{A}}\right),(0,0),\left(x_{\mathrm{C}}, y_{\mathrm{C}}\right)$. Location of the SIPs for selected GPS sites and GPS satellite numbers LUZH-14, LUZH-22 and XIAG-05 at the mo-
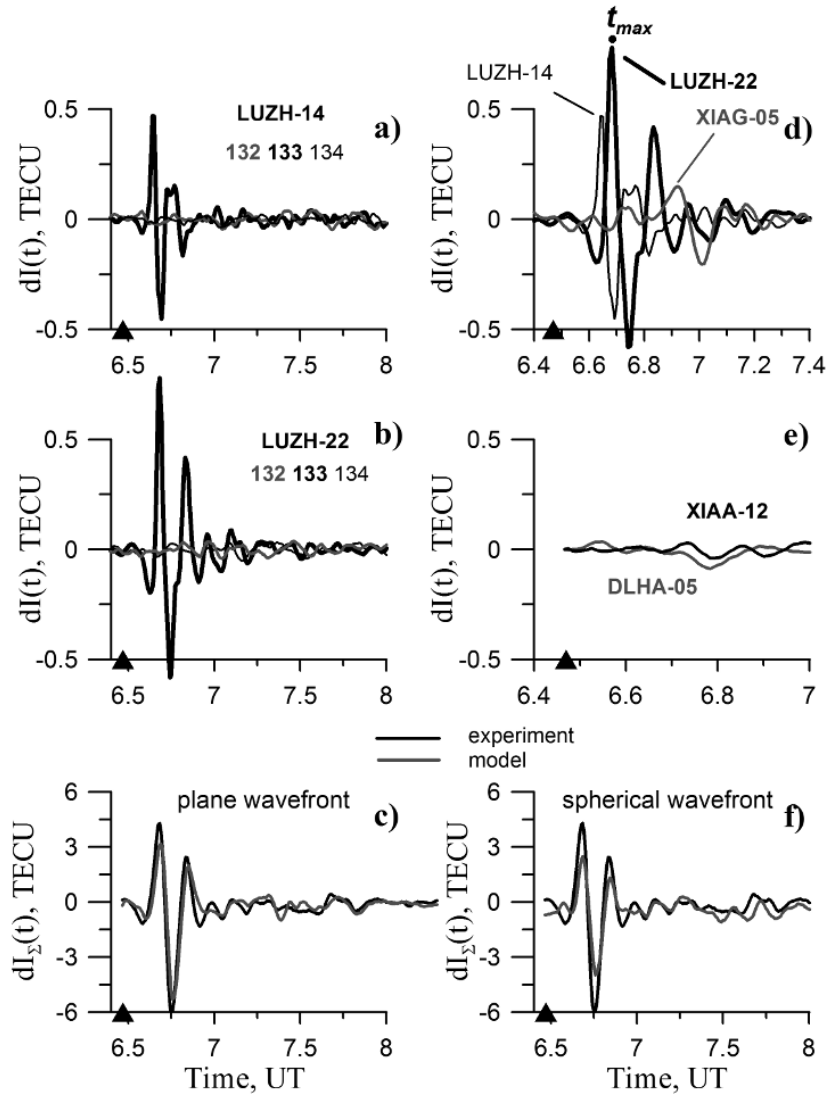

e)

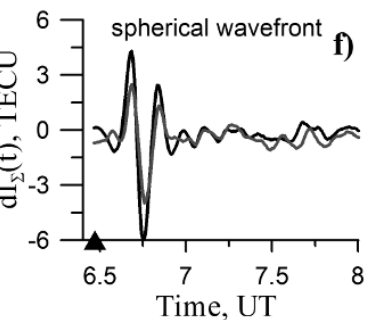

Fig. 2. The filtered TEC series $d I(t)$ for LUZH-14 (a), LUZH-22 (b) located in the southeast region from the epicenter; black, thin, and thick gray lines-11, 12 and 13 May, respectively. Time moment $t_{\max }$ of a maximum deviation of the $d I(t)$ is marked by thick dot. Panel (e) demonstrate the reduction of amplitude of responses in the northwest (DLHA-05) and northeast (XIAA-12) direction from epicenter. On the panels (c) and (f) the black line shows the accumulated TEC series $d I_{\Sigma}(t)$, obtained on the experimental stage of processing for the plane and spherical wavefront, respectively. The thick gray line on the panels (c) and (f) marks the modeled $d I_{\Sigma}(t)$ for which the maximum of function $C$ was reached. The moment of the main shock of the Wenchuan earthquake is marked by shaded triangle.

ment of maximum TEC deviation is shown in Fig. 1 by thick dots. In Fig. 1 we also marked trajectories of other subionospheric points located in the northwest region (DLHA-05) and northeast region (XIAA-12) from the epicenter.

The input data include series of slant TEC values $I_{\mathrm{A}}(t)$, $I_{\mathrm{B}}(t), I_{\mathrm{C}}(t)$, as well as corresponding series of elevation values $\theta_{\mathrm{S}}(t)$ and the azimuth $\alpha_{\mathrm{S}}(t)$ of the LOS. To eliminate spatiotemporal variations of the regular ionosphere, as well as trends introduced by orbital motion of the satellite, a procedure is used to remove the trend with the selected time window (10 $\mathrm{min}$ ) involving a preliminary smoothing of the initial series (the time window $2 \mathrm{~min}$ ). Elevation $\theta_{\mathrm{s}}(t)$ and azimuth $\alpha_{\mathrm{s}}(t)$ of the LOS are used to determine the location of the SIP. We use the transformation by Klobuchar (1986) for calculating of 'vertical' value TEC $I(t)$.

Figure 2 shows the filtered vertical TEC series $d I(t)$ for LUZH-14 (a), LUZH-22 (b); black thin, thick and gray lines for 11, 12 and 13 May, respectively. A typical halfperiod is about 180-210 s. The oscillation amplitude of about 1 TECU (TECU $\left.=10^{16} \mathrm{~m}^{-2}\right)$ is far in excess $(10$ 30 times) of the background TEC fluctuation intensity as 
seen on the days before and after the earthquake. In this case the minimal delay of the SAW response (for LUZH14) with respect to the time of the earthquake main shock is 10.5 min. Panel (e) demonstrates the reduction of amplitude of responses in the northwest (DLHA-05) and the northeast (XIAA-12) directions from the epicenter.

The TEC series $d I(t)$ for the LOS's LUZH-14, LUZH22 and XIAG-05 are used to determine the velocity and direction of TEC disturbance phase front travelling as 3 functions $d I_{\mathrm{A}}(t), d I_{\mathrm{B}}(t), d I_{\mathrm{C}}(t)$ (panel (d)). Taking good signal/noise ratio (much better than 1) into account, and knowing the coordinates of the array sites A, B and C, we determine the horizontal projection of the phase velocity $V$ from time shifts $t_{\max }$ of a maximum deviation of the filtered TEC series $d I(t)$. This is followed by a calculation of the $E$ - and $N$-components of $V_{x}$ and $V_{y}$, as well as the direction $\alpha$ in the range of angles $0-360^{\circ}$ and the modulus $V$ of the horizontal component of the SAW phase velocity

$$
\begin{aligned}
\alpha & =\arctan \left(V_{y} / V_{x}\right) \\
V_{h} & =\left|V_{x} V_{y}\right|\left(V_{x}^{2}+V_{y}^{2}\right)^{-1 / 2}
\end{aligned}
$$

where $V_{y}, V_{x}$ are the velocities of the phase front crossing the axes $x$ and $y$. The azimuth $\alpha$ of the wave vector is counted off from the northward in a clockwise direction.

The azimuth $\alpha$ of the wave vector shown in Fig. 1 by a thick gray arrow equals to $160^{\circ}$. One can see that the phase front of $N$-shaped disturbance is parallel with the rupture direction (from SW to NE). The phase velocity was found to be $583 \mathrm{~m} / \mathrm{s}$.

The $Q O A$ algorithm allows us to calculate a normalized criterion function $C$. Function $C$ is the ration of the energy of the GPS-array output signals obtained at a modelling stage to the energy obtained at an experimental stage of processing. Maximum value of $C$ is 1.0. At an experimental stage the output signal is formed as a result of summation of TEC series for each separate LOS of the array with the shifts maximizing the value of energy of accumulated signal:

$$
d I_{\Sigma}(t)=d I_{0}(t)+\sum_{i=1}^{M} d I_{i}\left(t-\tau_{i}\right)
$$

where $i=1,2, \ldots, M$ is the TEC series number, where $d I_{0}(t)$ is a central series to which all other series are summed, $\tau_{i}$ is the time delay shift of the $i$-th series; $M$ is the number of elements in the GPS-array. At a modeling stage the TEC series shifts are calculated within the model of the plane or spherical wave front of the perturbation propagating with constant velocity. The processing for the spherical wave front is described by Kiryushkin and Afraimovich (2007) in detail.

In the QAA method we firstly carried out the spatiotemporal processing of all TEC series for all 27 GPS stations within the approximation of a spherical wave front. We fixed the coordinates of the point source within the spherical wave model in the epicenter of earthquake. Then we find the propagation velocity of the ionospheric perturbation from the maximum value of the criterion parameter $C$.

In order to illustrate the process of the search of the propagation velocity we showed the graph $C(V)$ in Fig. 3(a)

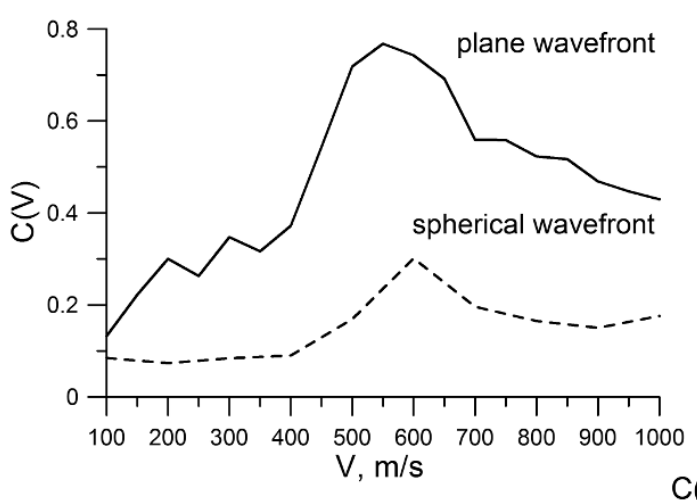

a)

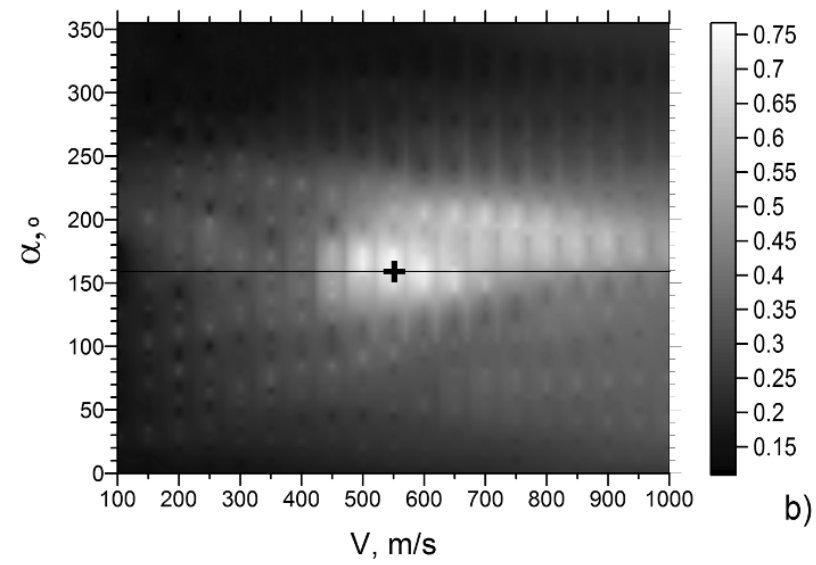

Fig. 3. (a) Criterion function $C(V)$ for the plane (solid line) and spherical (dotted line) wave front approximations. (b) 2D function $C(\alpha, V)$ for the plane wave front model; thin horizontal line mark cross section of $C(\alpha, V)$ corresponding to the dependence $C(V)$ for the plane wave form shown in panel (a). Maximum value $C(\alpha, V)_{\max }$ of about 0.8 (marked by cross) corresponds the values of velocity $V=560 \mathrm{~m} / \mathrm{s}$ and azimuth $\alpha=160^{\circ}$ of the wave front propagation.

(dotted line). The maximum value $C(V)=0.3$ was obtained at $V=600 \mathrm{~m} / \mathrm{s}$. However the small value of the criterion parameter illustrates the low degree of conformity for the model of the spherical front of the shock acoustic wave and ionospheric perturbation observed during the experiment. It agrees with insufficient correspondence between the experimental and model TEC series. The accumulated series $d I_{\Sigma}(t)$ for the experiment (black line) and model (gray line) are presented in Fig. 2(f).

Further, the spatiotemporal filtration of ionospheric responses in all TEC series was carried out at this phase of processing. The amplitude of TEC responses and coordinates of the corresponding SIPs was determined. It allowed us to construct the direction diagram of the epicentral emitter of the perturbation wave in the form of the dependence of maximum TEC amplitude $d I(t)_{\max }$ on corresponding direction azimuth $\alpha$ from the epicenter to the SIPs (Fig. 4(a)). In Fig. 4(a) the gray line marks the direction diagram $d I(t)_{\max }(\alpha)$. We found that maximal response to the main shock was registered in the southeast sector. Therefore we carried out the further processing only for 40 TEC series observed on the south from the epicenter of the earthquake.

We further used the model of a plane front of a shock acoustic wave. We carried out the simultaneous estimation of the arrival direction and the propagation velocity of the ionospheric perturbation from the maximum of the criterion 


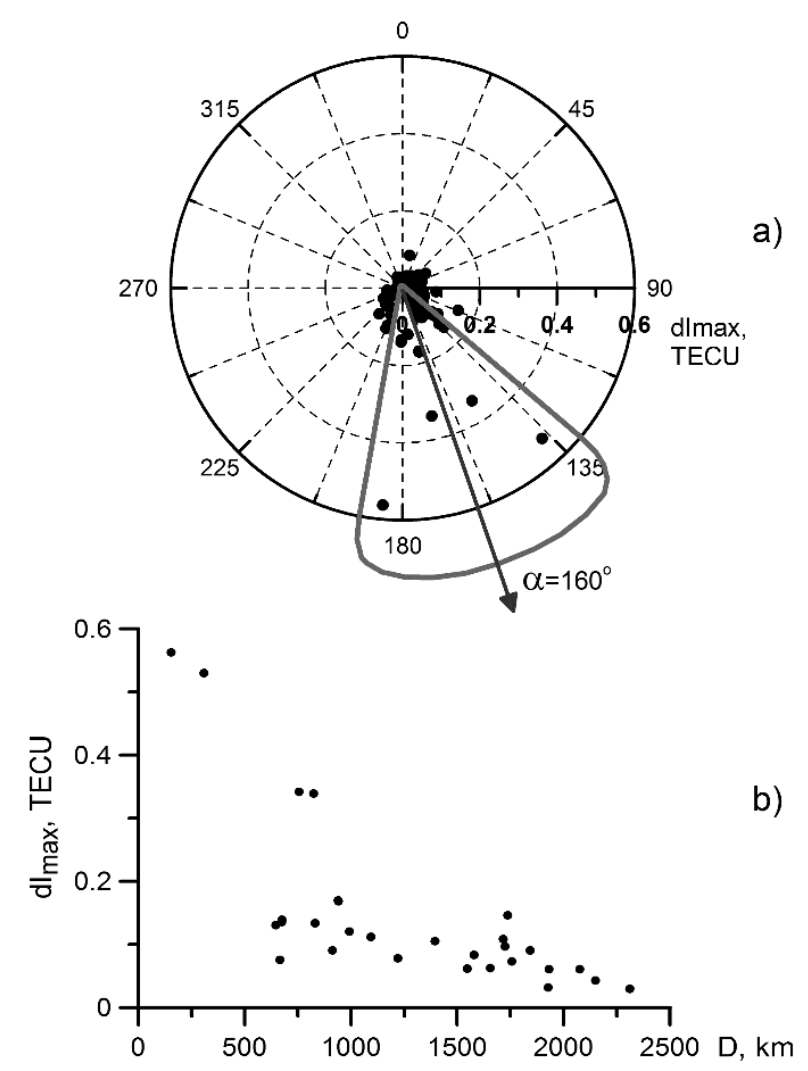

Fig. 4. (a) The distribution of maximum amplitude $d I(t)_{\max }$ on corresponding direction azimuth from epicenter to SIPs, obtained for all used GPS sites (86 SIPs); maximal response to the main shock was registered in southeast sector. Gray line marks the direction diagram $d I(t)_{\max }(\alpha)$. (b) Corresponding distribution of amplitude $d I(t)_{\max }$ on distance $D$ from epicenter along the great circle arc only for the southeast sector (40 SIPs).

parameter $C$. For the plane wave front we form the GPSarray direction diagram and direct it in the phase space $[\alpha, V]$, when assigning values of the arrival direction $\alpha$ and propagation velocity $V$ and carrying out the coherent accumulation of TEC series $d I(t)$.

The process of searching for the best $C$ is shown in Fig. 3(b) in the form of a $2 \mathrm{D}$ criterion function $C(\alpha, V)$. The maximum value $C(\alpha, V)_{\max }$ of about 0.8 (marked by cross) corresponds to the values of velocity $V=560 \mathrm{~m} / \mathrm{s}$ and azimuth $\alpha=160^{\circ}$ of the wave front propagation. It should be noted that these values coincide exactly with the ones obtained using the $D 1$ method. Thin horizontal line marks the cross section of $C(\alpha, V)$ corresponding to the dependence $C(V)$ for the plane waveform shown in Fig. 3(a) by solid line. The great value of criterion parameter illustrates the high degree of conformity of the model of the plane wave front and experimentally observed ionospheric perturbation.

The accumulated series $d I_{\Sigma}(t)$ for the experiment and the plane waveform model are presented in black line and gray line in Fig. 2(c), respectively. We can see full correspondence between the experiment and the model.

The distribution of amplitude $d I(t)_{\max }$ on distance $D$ from epicenter along the great circle arc (Fig. 4(b)) was constructed only for the SIPs located in southeast sector where the amplitude of responses is maximum. One can see that the amplitude $d I(t)_{\max }$ decreases with distance $D$ very quickly: in 5 times at distance $700-1000 \mathrm{~km}$.

\section{Discussion and Conclusion}

It is very interesting to compare the obtained characteristics of the TEC response to the Wenchuan earthquake with similar parameters for other strong earthquakes (Afraimovich et al., 2001a, 2006; Ducic et al., 2003; Heki et al., 2006; Otsuka et al., 2006; Kiryushkin and Afraimovich, 2007). General information about these earthquakes is presented in left part of Table 1 (including the time of the main shock in the universal time UT, the position of the earthquake epicenter, depth, the magnitude, as well as the level of geomagnetic disturbance from the data on $D_{\mathrm{st}^{-}}$ variations). It was found that the deviation of $D_{\text {st }}$ for the selected days was quite moderate, which enabled the SAWs to be identified.

General information about TEC response parameters is presented in the right part of Table 1 (including the $T$-SAW period; $A$-the maximum amplitude of absolute $d I$, [TECU], and relative $d I / I_{0}$, [\%], TEC deviation for selected LOS; the kind of wave front (plane or spherical); the horizontal component of the phase velocity $V$; the azimuth $\alpha$ of the SAW vector; the altitude $H_{\mathrm{e}}$ of a secondary source of the wave perturbation registered by GPS-array, for the spherical wave front approximation). The second column shows also the references. The relative amplitude $d I / I_{0}$ is determined by normalization of the $d I$ to the background value $I_{0}$, where $I_{0}$ is the absolute vertical TEC obtained with twohour time resolution from the global TEC maps in the IONEX format (so called Global Ionospheric Maps, GIM (ftp://cddisa.gsfc.nasa.gov/pub/gps/products/ionex/). The absolute $d I$ and relative $d I / I_{0}$ amplitude of TEC deviation increase with the increasing of earthquake's magnitude.

Afraimovich et al. (2001b) compared the TEC disturbances from the shock-acoustic waves generated during earthquakes (in Turkey on August 17 and November 12, 1999, in Southern Sumatra on June 4, 2000 and off the coast of Central America on January 13, 2001), rocket launchings and explosions (New Mexico power explosion on June 6, 1993), using our GPS-arrays method (Afraimovich et al., 2001a) for determining SAW parameters (including angular characteristics of the wave vector, and the SAW phase velocity). It was shown that, whatever the type of source, the impulsive TEC disturbance has the character of a classical $N$-wave with a period of 180-360 s, and with its amplitude exceeding the level of background fluctuations under moderate geomagnetic conditions by a factor of $2-5$ as a minimum. The phase velocity $(600-1200 \mathrm{~m} / \mathrm{s})$ approaches the sound velocity at the height of the ionospheric $F$-region maximum. So, the parameters of ionospheric response to impulsive impact are determined not only by the source characteristics but substantially by the properties of ionospheric channel of the shock-acoustic waves propagation.

Here, we want to compare TEC response observed during the Wenchuan earthquake with the Great Sumatra earthquake which occurred on 26 December, 2004. The ionospheric disturbance registered after the earthquake was very powerful (Heki et al., 2006; Otsuka et al., 2006) and is com- 
Table 1. General information about strong earthquakes and TEC response parameters.

\begin{tabular}{|c|c|c|c|c|c|c|c|c|c|c|}
\hline $\begin{array}{l}\text { Data } \\
\text { Day }\end{array}$ & $\begin{array}{l}\text { Region, } \\
M, \text { Ref. }\end{array}$ & Epic. & $\begin{array}{c}\text { Dep., } \\
\text { km }\end{array}$ & $t_{0}(\mathrm{UT})$ & $\begin{array}{c}D_{\text {st }}, \\
\mathrm{nT}\end{array}$ & $\begin{array}{c}T \\
\mathrm{sec}\end{array}$ & $\begin{array}{c}\text { LOS } \\
A, \text { TECU } / \% \\
\end{array}$ & Wavefront & $\begin{array}{c}V, \mathrm{~m} / \mathrm{s} \\
\alpha,^{\circ} \\
\end{array}$ & $\begin{array}{l}H_{\mathrm{e}}, \\
\mathrm{km}\end{array}$ \\
\hline $\begin{array}{l}17.08 .99 \\
229\end{array}$ & $\begin{array}{l}\text { Turkey, } \\
7.4,[1]\end{array}$ & $\begin{array}{l}40.7 \mathrm{~N} \\
29.9 \mathrm{E}\end{array}$ & 17 & 00:01:39 & -14 & 354 & $\begin{array}{c}\text { BSHM-06 } \\
0.28 / 2.5\end{array}$ & Plane & $\begin{array}{r}1173 \\
156\end{array}$ & - \\
\hline $\begin{array}{l}12.11 .99 \\
316\end{array}$ & $\begin{array}{l}\text { Turkey, } \\
7.1,[1]\end{array}$ & $\begin{array}{l}40.8 \mathrm{~N} \\
31.1 \mathrm{E} \\
\end{array}$ & 10 & $16: 57: 20$ & -44 & 195 & $\begin{array}{c}\text { GILB-30 } \\
0.2 / 1.4\end{array}$ & Plane & $\begin{array}{r}1157 \\
186 \\
\end{array}$ & - \\
\hline $\begin{array}{l}04.06 .00 \\
156\end{array}$ & $\begin{array}{l}\text { Sumatra, } \\
7.7,[1]\end{array}$ & $\begin{array}{l}4.7 \mathrm{~S} \\
102.1 \mathrm{E}\end{array}$ & 33 & $16: 28: 30$ & +8 & 260 & $\begin{array}{c}\text { NTUS-03 } \\
0.25 / 1.1\end{array}$ & Spherical & $\begin{array}{r}1048 \\
-\end{array}$ & 350 \\
\hline $\begin{array}{l}13.01 .01 \\
013\end{array}$ & $\begin{array}{l}\text { Salvador, } \\
7.6,[1]\end{array}$ & $\begin{array}{l}12.8 \mathrm{~N} \\
88.8 \mathrm{~W}\end{array}$ & 39 & $17: 33: 32$ & +4 & 240 & $\begin{array}{c}\text { MANA-13 } \\
0.35 / 0.7\end{array}$ & Plane & - & - \\
\hline $\begin{array}{l}25.09 .03 \\
268\end{array}$ & $\begin{array}{l}\text { Hokkaido, } \\
8.3,[2]\end{array}$ & $\begin{array}{l}41.8 \mathrm{~N} \\
143.9 \mathrm{E}\end{array}$ & 33 & 19:50:06 & +21 & 626 & $\begin{array}{c}\text { MIZU-24 } \\
0.26 / 2.3\end{array}$ & Spherical & $\begin{array}{r}820 \\
-\end{array}$ & 340 \\
\hline $\begin{array}{l}05.09 .04 \\
249 \\
\end{array}$ & $\begin{array}{l}\text { Honshu, } \\
7.4,[2]\end{array}$ & $\begin{array}{l}33.19 \mathrm{~N} \\
137.06 \mathrm{E}\end{array}$ & 10 & $14: 57: 18$ & -38 & 612 & $\begin{array}{c}\text { USUD-07 } \\
0.1 / 0.7\end{array}$ & Spherical & $\begin{array}{l}460 \\
- \\
\end{array}$ & 370 \\
\hline $\begin{array}{l}26.12 .04 \\
361\end{array}$ & $\begin{array}{l}\text { Sumatra, } \\
9.3,[3]\end{array}$ & $\begin{array}{l}3.29 \mathrm{~N} \\
95.78 \mathrm{E}\end{array}$ & 30 & $00: 58: 53$ & -18 & 270 & $\begin{array}{c}\text { SAMP-13 } \\
6.9 / 50\end{array}$ & Spherical & $\begin{array}{l}250 \\
- \\
\end{array}$ & - \\
\hline $\begin{array}{l}12.05 .08 \\
133\end{array}$ & $\begin{array}{l}\text { Wenchuan, } \\
7.9,[4]\end{array}$ & $\begin{array}{l}30.98 \mathrm{~N} \\
103.36 \mathrm{E}\end{array}$ & 19 & $06: 28: 01$ & -3 & 400 & $\begin{array}{c}\text { LUZH-22 } \\
1.3 / 7.6\end{array}$ & Plane & $\begin{array}{l}580 \\
160\end{array}$ & - \\
\hline
\end{tabular}

[1] Afraimovich et al. (2001a);

[2] Afraimovich et al. (2006), Kiryushkin and Afraimovich (2007);

[3] Heki et al. (2006), Otsuka et al. (2006);

[4] Present paper.

mensurable with the response to the Wenchuan earthquake. Heki et al. (2006) and Otsuka et al. (2006) found anisotropy in the TEC variations with respect to the azimuth from the epicenter. Large TEC enhancements (1 TECU) were observed on the north of the epicenter. On the south of the epicenter, on the contrary, TEC was only slightly enhanced, by 0.6 TECU, and TEC enhancement was not seen on the east of the epicenter. However, in this case the authors connected the observed anisotropy of the TEC variations with anisotropy in the response of the electron density variation to the neutral motion of acoustic waves in oblique geomagnetic field lines.

In order to estimate a degree of influence of Earth magnetic field on the directional properties of the ionospheric perturbation, generated during the 2008 Wenchuan earthquake, we determined a direction of the magnetic lines near to the earthquake epicenter using the IGRF model (Maus and Macmillan, 2005). It was found that at the height of $300 \mathrm{~km}$ the declination of the magnetic field vector was equal to $-2.11^{\circ}$, and the inclination was $-47.2^{\circ}$. We showed the projection of the magnetic field vector $\boldsymbol{B}$ to Earth's surface by dotted grey arrow in Fig. 1. The analysis of the obtained data allows us to conclude that in this experiment the geomagnetic field did not influence on the directional properties of the ionospheric perturbation predominantly. Otherwise the greatest intensity of the ionospheric response would be observed in the northern and northwestern sectors from epicenter, i.e. where the direction of the propagation of the ionospheric perturbation coincided with the direction of the magnetic field lines.

So, using GPS TEC measurements from the Crustal Movement Observation Network of China, for the first time, we have registered near-field TEC response to the Wenchuan earthquake on 12 May 2008. We found that an intensive $N$-shape shock-acoustic wave with a plane waveform and with half-period of about $200 \mathrm{sec}$ propagated south-eastward with a velocity of $600 \mathrm{~m} / \mathrm{s}$ for distance about $1000 \mathrm{~km}$. The wave front of $N$-shaped disturbance was parallel with the earthquake rupture direction (from SW to NE). The main directional lobe of shock-acoustic wave emitter is directed southeastward, i.e. transversely to the rupture.

We suppose that the above properties of TEC response are determined by the geodynamics of the Wenchuan earthquake. Detailed investigation of that phenomenon and corresponding modelling are the aims of our future works.

Acknowledgments. The work was supported by the Interdisciplinary integral project of SB RAS N 56 "Seismoionospheric and seismoelectromagnetic processes in Baikal Rift Zone", the RFBRGFEN grant N 06-05-39026 and RFBR grant 07-05-00127; by the Japanese Society for the Promotion of Science (JSPS); by the National Natural Science Foundation of China (grants 40774090 and 40636032) and the National Important basic Research Project (2006CB806306).

\section{References}

Afraimovich, E. L., GPS global detection of the ionospheric response to solar flares, Radio Sci., 35(6), 1417-1424, 2000.

Afraimovich, E. L., N. P. Perevalova, A. V. Plotnikov, and A. M. Uralov, The shock-acoustic waves generated by the earthquakes, Ann. Geophys., 19, 395-409, 2001a.

Afraimovich, E. L., E. A. Kosogorov, N. P. Perevalova, and A. V. Plotnikov, Comparison of TEC response of the shock-acoustic waves generated during rocket launchings, by earthquakes and explosions. Proceedings of International Beacon Satellite Symposium, 4-6 June 2001, Boston College, Institute for Scientific Research, Chestnut Hill, MA, USA, 373-377, 2001b.

Afraimovich, E. L., V. V. Kiryushkin, and N. P. Perevalova, Determination of the Characteristics of Ionospheric Perturbations in the Near-Field Region of an Earthquake Epicenter, J. Comm. Tech. Electron., 47, 739$747,2002$. 
Afraimovich, E. L., E. I. Astafyeva, and V. V. Kiryushkin, Localization of the source of ionospheric disturbance generated during an earthquake, Int. J. Geomagn. Aeron., 6, GI2002, doi:10.1029/2004GI000092, 2006.

Calais, E. and J. B. Minster, GPS detection of ionospheric perturbations following the January 1994, Northridge earthquake, Geophys. Res. Lett., 22, 1045-1048, 1995.

Ducic, V., J. Artru, and P. Lognonne, Ionospheric remote sensing of the Denali earthquake Rayleigh surface waves, Geophys. Res. Lett., 30(18), 1951, doi:10.1029/2003GL017812, 2003.

Heki, K., Y. Otsuka, N. Choosakul, N. Hemmakorn, T. Komolmis, and T. Maruyama, Detection of ruptures of Andaman fault segments in the 2004 great Sumatra earthquake with coseismic ionospheric disturbances, J. Geophys. Res., 111, B09313, doi:10.1029/2005JB004202, 2006.

Ji, Ch. and G. Hayes, Preliminary result of the May 12,2008 Mw 7.9 eastern Sichuan, China earthquake, http://earthquake.usgs.gov/ eqcenter/eqinthenews/2008/us2008ryan/finitefault.php, 2008.

Kiryushkin, V. V. and E. L. Afraimovich, Determining the parameters of ionospheric perturbation caused by earthquakes with using the quasi- optimum algorithm of spatio-temporal processing of TEC measurements, Earth Planets Space, 59, 267-278, 2007.

Klobuchar, J. A., Ionospheric time-delay algorithm for single-frequency GPS users, IEEE Trans. Aerospace Electron. Syst., 23(3), 325-331, 1986.

Otsuka, Y., N. Kotake, T. Tsugawa, K. Shiokama, T. Ogawa, Effendy, S. Saito, M. Kawamura, T. Maruyama, N. Hemmakorn, and T. Komolmis, GPS detection of total electron content variations over Indonesia and Thailand following the 26 December 2004 earthquake, Earth Planets Space, 58, 159-165, 2006.

Parsons, T., Ch. Ji, and E. Kirby, Stress changes from the 2008 Wenchuan earthquake and increased hazard in the Sichuan basin, Nature, 454, 509510, doi:10.1038, 2008.

Maus, S. and S. Macmillan, International geomagnetic reference field-the tenth 566 generation, Earth Planets Space, 57(12), 1135-1140, 2005.

E. L. Afraimovich, D. Feng, V. V. Kiryushkin (e-mail: kiryushkin.vlad@mail.ru), and E. I. Astafyeva 